\title{
The influence of anaerobic muscle activity, maturation and season on the flesh quality of farmed turbot
}

\author{
Bjorn Roth • Albert Imsland • Lars Helge Stien • Rian Schelvis-Smit • \\ Snorri Gunnarsson · Atle Foss
}

Received: 5 August 2008/Accepted: 30 March 2009/Published online: 21 April 2009

(C) The Author(s) 2009. This article is published with open access at Springerlink.com

\begin{abstract}
In order to test seasonal, rearing, maturing and anaerobic muscle activity effect on the flesh quality of turbot (Scophthalmus maximus) a total of 80 farmed turbot from three different strains from reared under natural or continuous light were killed by a percussive blow to the head in November (winter, Icelandic strain), March (spring, Portuguese strain) and June (summer, domesticated strain (France turbot)). To test the effect of anaerobic muscle activity, 10 fish were on each occasion pre rigor filleted, where one fillet was used as a control, while the other fillet was electrically stimulated using a squared $5 \mathrm{~Hz}, 10 \mathrm{~V}$ pulsed DC for $3 \mathrm{~min}$. All pre rigor fillets were measured for $\mathrm{pH}$, weighed, wrapped in aluminum foil and stored in polystyrene boxes with ice. After 7 days of storage the fillets were measured instrumentally for $\mathrm{pH}$, drip loss, colour (CIE $L^{*} a^{*} b^{*}$ ) and texture properties such as hardness and shear force, while fillet shrinkage and colour (RBG) were evaluated with computer imaging on photographs from a standard lightbox. Results showed that softness of the flesh was mainly influenced by factors associated with growth, such as season, photoperiod and maturation. Anaerobic muscle activity simulated with electrical stimulation caused an increase in drip loss $(<1 \%)$ and loss of shear force
\end{abstract}

B. Roth · A. Imsland

Department of Biology, University of Bergen, 5020 Bergen, Norway

B. Roth (西)

Nofima Norconserv A/S, P.O. Box 327, 4002 Stavanger, Norway

e-mail: bjorn.roth@nofima.no

A. Imsland $\cdot$ S. Gunnarsson

Akvaplan Niva, Iceland Office, Akralind 4, 201 Kopavogur, Iceland

L. H. Stien

Institute of Marine Research, 5817 Bergen, Norway

R. Schelvis-Smit

Wageningen IMARES, Institute for Marine Resources \& Ecosystem Studies, 1970 AB IJmuiden, The Netherlands

A. Foss

Akvaplan-Niva Bergen, 5817 Bergen, Norway 
$(<4 \%)$, but had no effect on hardness or fillet shrinkage. Computer imaging revealed that muscle contractions related to the electrical stimulus forced out blood from the fillet causing less reddishness for the entire storage period. We conclude that a $\mathrm{pH}$ drop upon slaughter associated with anaerobic muscle activity has a minor effect on the flesh quality in the short run, while seasonal/alternatively genetic effects are predominant.

Keywords Electric stimulation · Fish · Quality - Season · Mature ·

Texture · Drip loss

\section{Introduction}

It is generally accepted that the flesh quality of fish is influenced by many factors such as stress (Boggess et al. 1973; Kiessling et al. 2004; Azam et al. 1989), feeding regime and season (Lavety et al. 1988; Morkore and Rorvik 2001; Love 1975; Espe et al. 2004; Hagen et al. 2007). Electric trial stimulation is becoming more widely used to fatigue the muscles in fish in order to gain more understanding how anaerobic muscle activity affects the flesh quality for species like Chinook salmon (Oncorhynchus tshawytscha) (Fletcher et al. 1997; Jerrett et al. 1996, 1998; Jerrett and Holland 1998), rainbow trout (Oncorhynchus mykiss) (Robb et al. 2000) and Atlantic salmon (Salmo salar) (Roth et al. 2006, 2008). Electrical stimulation of muscle tissue causes a rapid depletion of high energy phosphogenes like adenosine triphosphate (ATP) and phosphocreatine (PCr) (Proctor and McLoughlin 1992; Chiba et al. 1990) followed by acidification of the muscle, rapid onset of rigor mortis $(<2 \mathrm{~h})$, loss of colour and pronounced gaping (Fletcher et al. 1997; Jerrett et al. 1996, 1998; Jerrett and Holland 1998; Robb et al. 2000; Roth et al. 2006, 2008).

Although growth rate appears to have little influence on gaping and shear forces (Johnston et al. 2007), seasonal changes in flesh quality are possibly related to changes in muscle pH (Lavety et al. 1988), collagen content (Espe et al. 2004; Hagen et al. 2007) and size (Love 1975; Veland and Torrissen 1999). For turbot it has been shown that both pre mortem stress or anaerobic muscle activity caused by electrical stimulation has very little impact on the flesh quality (Ruff et al. 2002a; Morzel et al. 2003; Roth et al. 2007a). One possible explanation is that turbot are inactive upon slaughter and has a very high initial and end $\mathrm{pH}$ as compared to other species such as Atlantic halibut (Hippoglossus hippoglossus) (Ruff et al. 2002b).

The aim of this study was therefore to investigate the effect of electrical stimulation on the quality of turbot fillets collected from fish of a uniform size at different times of the year and measure changes in muscle $\mathrm{pH}$, rigor contraction, fillet shrinkage, colour, water retention, textural shear force and hardness.

\section{Materials and methods}

Market size turbot $(0.7-2.0 \mathrm{~kg})$ were slaughtered at commercial turbot farms in Iceland (Silfurstjarnan Ltd.), Portugal (A.Coelho e Castro Ltd.) and Germany (Ecomares GMBH) in November 2005, March 2006 and June 2006, respectively. To sample fish of similar size with various background, 2 groups of fish were harvested in Iceland, hatched in June 2003 $(n=10)$ and $2004(n=10)$ at the Icelandic Marine Institute and all fish were reared under natural day light (LDN). All fish in Iceland originated from a natural population of turbot caught outside Iceland. In Portugal, the fish originating from the North west coast of 
Portugal were harvested in March 2006. These fish were hatched in June 2004 and were reared under either LDN ( $n=30)$ or continuous daylight (LD24:0, 300 lux) $(n=20)$. In Germany ten fish was harvested in June 2006. This fish originated from a domesticated stock (France turbot) hatched in July 2005 and reared under LDN until slaughter. Previous studies on turbot verifies a genetic diversity between domesticated turbot and natural population of fish found outside the West coast of Spain, and also between the natural population of turbot found at the Cantabric sea (Bouza et al. 2002). This gives reason to believe that the fish from Iceland is genetically different to the fish in Portugal and furthermore different from the domesticated stock, hence three different populations of turbot.

In Iceland, Portugal and Germany 10 fish reared under LDN were killed and pre rigor filleted and used in electrical stimulation trial, whereas the rest were stored whole on ice and filleted after 7 days before measuring shear force. Whole weight, sex, maturation, muscle $\mathrm{pH}$ at slaughter (initial $\mathrm{pH}$ ) and after 7 days (end $\mathrm{pH}$ ) were noted in all fish. As described above, in addition to sampling for pre rigor filleting, fish subjected for LDN in Iceland $(n=10)$, Portugal $(n=20)$ and 24:0 in Portugal $(n=20)$ were killed as described and exsanguinated in ice slurry before the fish was stored whole in polystyreneboxes with ice, stored for 7 days before post rigor filleting.

In November and March the rearing temperature was $14^{\circ} \mathrm{C}$ and salinity was approximately 31 and $34 \mathrm{ppt}$, respectively. In June the water salinity was $32 \mathrm{ppt}$ and the temperature was $18^{\circ} \mathrm{C}$.

In order to obtain knowledge on how anaerobic muscle activity affects the flesh quality, a total of ten fish were taken from its rearing tank on each location and killed by a sharp blow to the head. The fish was then weighed and filleted. The first fillet including the whole side (dark or light side) was used as a control (C), whereas the second fillet was electrically stimulated (E), while still on the carcass. For electrical stimulation, a pulse generator made by ARENA A/S (inc), Austevoll, Norway was used. The apparatus provided a pure squared direct current (pDC), max 26 Volts (V) root mean square (rms), max 5 amps (A) with frequencies $(f)$ between $1-80 \mathrm{~Hz}$. The dutycycle of the square pulses was set to $50 \%$ providing a pulse length $(\mathrm{ms})=1,000 /(2 f) \mathrm{ms}$. The potential difference was set to $10 \mathrm{~V}_{\mathrm{rms}}$ while peak values where exactly twice as high as rms values $\left(20 \mathrm{~V}_{\text {peak }}\right)$ and frequency set to $5 \mathrm{~Hz}$. The electrical stimulation was carried out on carcasses by placing the anode into the neurocranium and the cathode into the vertebrae by the tail (Roth et al. 2007a). Two electrodes (anodes) were placed on the outer parts of the fillets to ensure a more homogenous electric field. The electric stimulation started approximately 5 min post mortem and the duration of the electrical stimulus was 3 min.

Immediately after electric stimulation, the fillet was filleted off the carcass, and both fillets were weighed $\left(W_{0}\right)$, muscle $\mathrm{pH}$ was measured, and the fillets were packed in aluminum foil and placed in polystyrene boxes with ice and stored in a refrigerator $\left(4^{\circ} \mathrm{C}\right)$ for 7 days, before quality analyses commenced.

\section{Quality analysis}

After 7 days of storage, fillet shrinkage, drip loss, muscle $\mathrm{pH}$, colour, shear force and hardness was analysed.

Computer imaging: Fillet shrinkage and colour

For computer imaging, the fillets from Iceland were photographed in a photobox using a digital camera (Canon EOS 300d DIGITAL) immediately after filleting and after 7 day 
post mortem. The photobox provided uniform and diffuse lighting on the fillets in order to avoid reflexes on the moist and shiny fillet surfaces. The photobox also ensured that the lighting was identical from image to image $(T=6,500 \mathrm{~K}, \mathrm{Ra} \geq 90)$. The output from the camera was RGB-colour-images. Each pixel $(x, y)$ in an RGB-colour-image is a triplet corresponding to the intensity of the primary colours (R)ed, $(\mathrm{G})$ reen and (B)lue at that point. The intensities were in the range $(0,1, \ldots, 255)$. The fully automatic image analysis of each image consisted of three steps: First, all light pixels where identified as fillet (1) and all others as background (0):

$$
b(x, y)=\left\{\begin{array}{l}
1 \Leftrightarrow(\mathrm{R}(x, y)+\mathrm{G}(x, y)+(\mathrm{B}(x, y)) / 3>50 \\
0 \quad \text { otherwise }
\end{array}\right.
$$

The intensity of red was larger than the two other intensities for all pixels in the fillet regions. It was therefore decided to use this difference as a measure of how red the individual pixels were:

$$
f(x, y)=(\mathrm{R}(x, y)-(\mathrm{G}(x, y)+\mathrm{B}(x, y)) / 2) b(x, y)
$$

Pixels with $f<70$ were visually judged to have a whitish colour, pixels with $70 \leq f<100$ as reddish and $f \geq 100$ as dark red. The following ratios where therefore calculated to describe the colour of the fillet region:

$$
p(\text { white })=100 \sum_{k=1}^{69} \frac{n_{k}}{n}, \quad p(\text { reddish })=100 \sum_{k=70}^{99} \frac{n_{k}}{n}, \quad p(\text { red })=100 \sum_{k=100}^{255} \frac{n_{k}}{n}
$$

where $n_{k}$ is the number of pixels in $f$ equal $k$ and $n$ is the number of pixels in $f>0$.

Shrinkage was defined by changes of the total area, thus changes of the number of pixels in $\%$ from the initial size.

Muscle $\mathrm{pH}$

For measuring muscle $\mathrm{pH}$, an X-Mate portable metre and Inlab $489 \mathrm{pH}$ probe from Mettler Toledo $^{\mathrm{TM}}$ was used. Muscle $\mathrm{pH}$ was measured in white muscle tissue at the cranial part of the loin orientating from the dorsal back.

Colour $L^{*} a^{*} b^{*}$

Colour, represented as CIE $L^{*} a^{*} b^{*}$ values, were measured at three locations along the loin on the dorsal back (cranial, mid and caudal) using a Minolta Chroma Meter CR-200 (Minolta, Osaka, Japan). Measurements were made directly on the fillets using light source $\mathrm{D}$, and the measuring head was rotated $90^{\circ}$ between duplicate. $L^{*}$ represents lightness, $a^{*}$ the red-blue axis, and $b^{*}$ the yellow-green axis.

Drip loss

Drip loss (DL) was calculated according to the following formula DL $=\left[\left(W_{0}-W_{1}\right) /\right.$ $\left.W_{0}\right] \times 100$, were $W_{0}$ represents initial fillet weight and $W_{1}$ fillet weight at 7 days post mortem. 
Texture analysis

For texture measurements, shear force (blade) and hardness (puncture) were evaluated separately using an TA-XT2 ${ }^{\circledR}$-pro Texture Analyzer from Stable Micro Systems, UK with a load cell of $25 \mathrm{~kg}$ (Iceland) and $50 \mathrm{~kg}$ (Portugal and Germany). For measuring texture hardness, a flat cylinder, $20 \mathrm{~mm}$ in diameter was used as test probe. The penetration depth for the probe was $80 \%$ in Portugal and Germany. The cylinder was compressed at a constant speed equal to $1 \mathrm{~mm} / \mathrm{s}$. The texture profile was sampled at 3 locations directly on the ventral fillet along the loin, starting $1 \mathrm{~cm}$ behind the visceral cavity and moving towards the caudal region having $1 \mathrm{~cm}$ in distance between each replicate.

Shear force measurements were made using a $3 \times 70 \mathrm{~mm}$ blade with a $60^{\circ} \mathrm{knife}$ edge, slicing standard muscle samples $(69 \times 26 \mathrm{~mm})$ at a constant speed of $0.8 \mathrm{~mm} / \mathrm{s}$ (Sigurgisladottir et al. 2001). Two standard muscle samples from the loin of each fish were cut out just in front of or behind the fillet midpoint (Roth et al. 2007a). Skin and red muscle tissue was then removed. Each muscle sample was sliced at two locations, providing a total of four shear force samples per fillet (1-2 cranial, 3-4 caudal). The shear force was determined by the maximum force $(N)$ recorded when the knife sliced through the sample.

\section{Statistics}

A one way and factorial ANOVA was used for testing continuous variables such as drip loss and muscle $\mathrm{pH}$, depending on the number of categorical factors used such as season and treatment. For comparing shear force and hardness at a given compression towards categorical factors such as season, treatment, sex and maturation, the sample height, weigh, muscle $\mathrm{pH}$ were incorporated as covariates into the factorial ANOVA (ANCOVA). For testing differences within on categorical factor in ANOVA, Tukey post hoc analysis was used, while testing within several categorical factors Newman Keuls test of multiple ranges was used. To test differences between control and electrically stimulated fillets from the same fish, a paired $t$-test was used.

\section{Results}

There were significant differences in size between the various experimental groups (Table 1), where pre rigor filleted fish slaughtered in November 2005 were significant smaller than all other groups $(P<0.05$, Tukey post hoc $)$ and post rigor filleted fish subjected for LDN in March was significant larger $(P<0.05$, Tukey post hoc $)$.

In November 2005, fifty percent of the males did show small signs of maturation, where the gonads had stared to develop, although still very small in size. In March 2006 there were, however, clear signs of maturation, where the fish had developed gonads and in some case the fish were close to spawning. As shown in Table 1, fish farmed under LDN displayed better growth than fish subjected for continuous light, with the latter being significantly smaller $(P<0.05$, Tukey post hoc $)$. Both males and females subjected for LDN were undergoing full maturation, but for fish subjected for continuous light, only 2 out of 10 males had started to develop gonads and all the females were still immature $(n=10)$. 


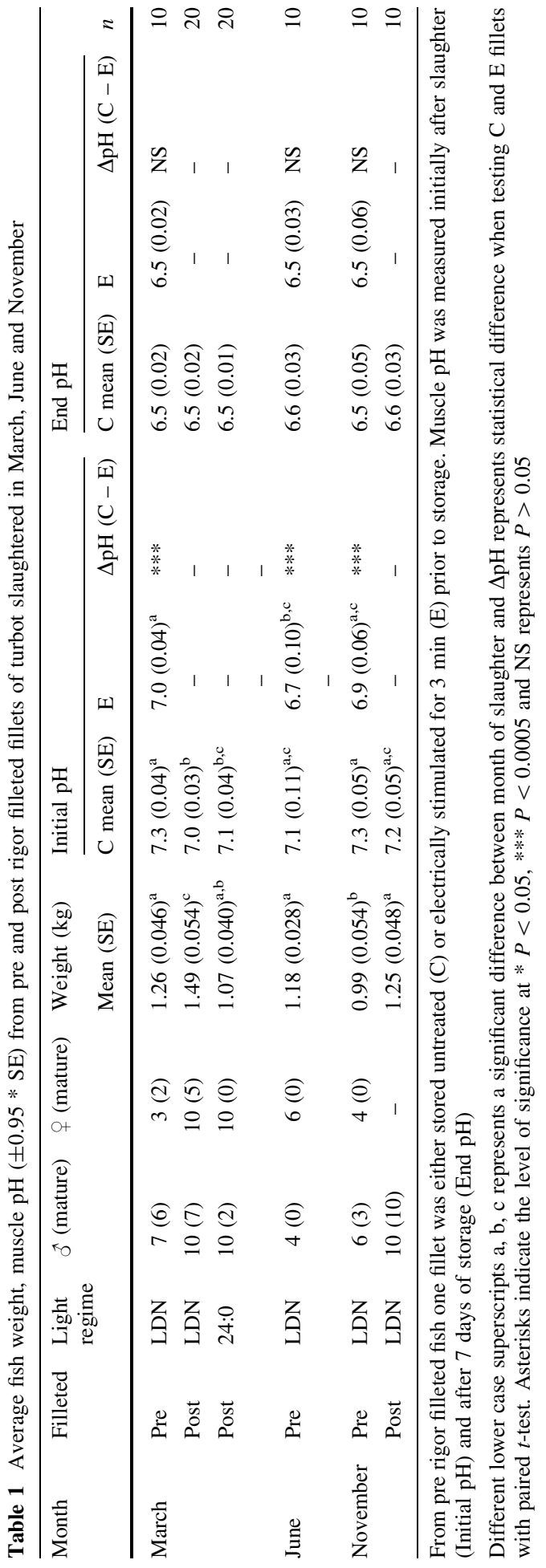


Muscle $\mathrm{pH}$

As shown in Table 1, there were, no significant differences in muscle $\mathrm{pH}$ between pre rigor filleted fish slaughtered at different times of the year $(P>0.72$, Tukey post hoc $)$. However, in March the fish sampled for post rigor filleting had significant lower muscle $\mathrm{pH}$ than fish sampled for pre rigor filleting indicating a higher sampling stress $(P<0.005$, Tukey post hoc). There was a slight difference in end $\mathrm{pH}$ were fish slaughtered in March was 0.06 and 0.08 units lower than fish slaughtered in June and November $(P<0.0005$, one way ANOVA), receptively.

During onset of the electrical stimulation, the muscles contracted well according to the applied frequency having approximately five contractions per second before the muscles responses gradually weakened until the muscles were completely fatigued within $2 \mathrm{~min}$. After 3 min of electrical stimulation, the muscle $\mathrm{pH}$ had an average drop of 0.42 units $(P<0.0005$, paired $t$-test, Table 1$)$. After 7 days of storage there were no significant differences between control or electrically stimulated fillets $(P>0.40$, paired $t$-test).

\section{Drip loss}

Electric stimulation caused a $1 \%$ increase in drip loss $(P<0.005$, paired $t$-test, Fig. 1$)$ in November and a $0.7 \%$ increase in June $(P<0.5$, paired $t$-test, Fig. 1$)$. There was no significant difference in drip loss between fish slaughtered in June and November $(P>0.05$, factorial ANOVA, Fig. 1).

Computer imaging: fillet shrinkage

Computer imaging analysis (Table 2) showed no difference in fillet shrinkage between control and electrically stimulated fillets $(P>0.52$, paired $t$-test $)$ or between different fillets tested (dark or light sided fillet) $(P>0.54$, factorial ANOVA).

Colour: Minolta and computer imaging

Electric stimulation resulted in higher $L^{*}$ values $(P<0.0005$, paired $t$-test $)$ and lower $a^{*}$ values $(P<0.005$, paired $t$-test $)$ than non stimulated fillets, whereas no significant

Fig. 1 Average drip loss (\%) $\pm 0.95 * \mathrm{SE}$ (whiskers) from pre rigor filleted fillets of turbot slaughtered in March $(n=10)$ and June $(n=10)$. Each fish provided two fillets, where one fillet were either stored untreated (C) or electrically stimulated for 3 min (E) prior to storage. Different lower case superscripts a, b represents a significant difference between $\mathrm{C}$ and $\mathrm{E}$ fillets at $* P<0.05, * * P<0.005$ and $* * * P<0.0005$

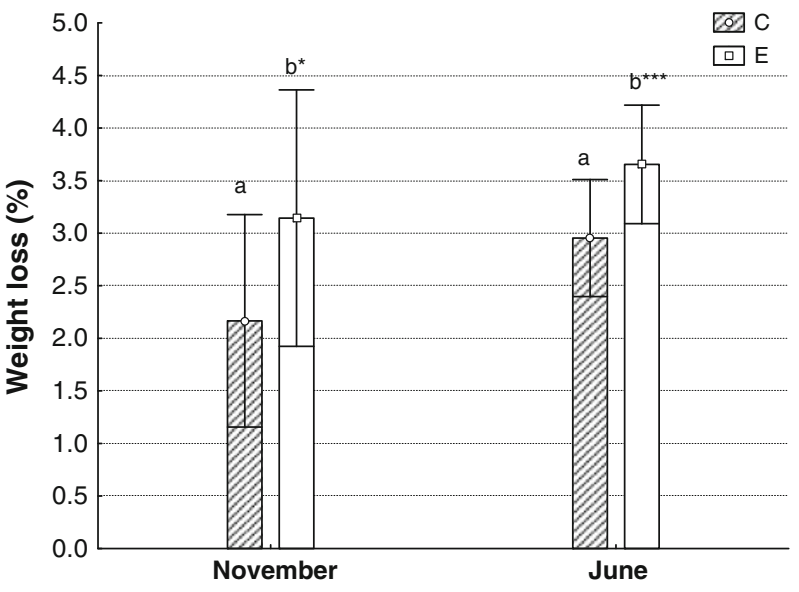


Table 2 Percentage whiteness, reddishness and redness and shrinkage of turbot fillets either stored untreated $(\mathrm{C})$ or electrically stimulated $(\mathrm{E})$

\begin{tabular}{|c|c|c|c|c|c|c|c|c|c|c|}
\hline \multirow[t]{2}{*}{ Day } & \multirow[t]{2}{*}{ Treatment } & \multicolumn{2}{|c|}{ Grey/whiteness } & \multicolumn{2}{|c|}{ Redishness } & \multicolumn{2}{|c|}{ Redness } & \multicolumn{2}{|c|}{ Shrinkage $(\%)$} & \multirow[b]{2}{*}{$n$} \\
\hline & & Mean & SE & Mean & SE & Mean & SE & Mean & SE & \\
\hline \multirow[t]{2}{*}{0 days } & $\mathrm{C}$ & $80.7^{\mathrm{a}}$ & 5.07 & $19.0^{\mathrm{a}}$ & 4.92 & $0.4^{\mathrm{a}}$ & 0.15 & - & - & 9 \\
\hline & $\mathrm{E}$ & $87.4^{\mathrm{b}} *$ & 3.89 & $12.5^{\mathrm{b} *}$ & 3.86 & $0.1^{\mathrm{b}_{*}}$ & 0.04 & - & - & \\
\hline \multirow[t]{2}{*}{7 days } & $\mathrm{C}$ & $87.3^{\mathrm{X}}$ & 2.87 & $12.7^{\mathrm{X}}$ & 2.85 & $0.1^{\mathrm{X}}$ & 0.03 & $14^{\mathrm{X}}$ & 0.9 & 9 \\
\hline & $\mathrm{E}$ & $92.7^{\mathrm{Y} *}$ & 1.75 & $7.3^{\mathrm{Y} *}$ & 1.75 & $0.0^{\mathrm{Y}_{*}}$ & 0.01 & $13^{\mathrm{X}}$ & 1.0 & \\
\hline \multicolumn{2}{|c|}{0 versus 7 days } & \multicolumn{2}{|l|}{$* *$} & \multicolumn{2}{|l|}{$* *$} & \multicolumn{2}{|l|}{$* *$} & \multicolumn{2}{|l|}{-} & \\
\hline
\end{tabular}

Shrinkage represents the percentage contraction from original length. Values are given in mean $\pm 0.95 * \mathrm{SE}$ In each column different lower case superscripts a, b or higher case superscripts $X$, Y represents a significant difference of $* P<0.05$ and $* * P<0.005$, tested with a paired $t$-test

Table 3 Average colour measured as $L^{*}, a^{*}, b^{*}( \pm 0.95 * \mathrm{SE})$ from pre rigor filleted fillets of turbot slaughtered in March $(n=10)$

\begin{tabular}{|c|c|c|c|c|c|c|c|}
\hline & \multicolumn{2}{|l|}{$L^{*}$} & \multicolumn{2}{|l|}{$a^{*}$} & \multicolumn{2}{|l|}{$b^{*}$} & \multirow[b]{2}{*}{$N$} \\
\hline & Mean & SE & Mean & SE & Mean & $\mathrm{SE}$ & \\
\hline Control & $55.4^{\mathrm{a}}$ & 0.49 & $-1.4^{\mathrm{a}}$ & 0.12 & $-2.2^{\mathrm{a}}$ & 0.36 & \\
\hline El-stim & $59.0^{\mathrm{b}} * * *$ & 0.40 & $-1.7^{\mathrm{b} * *}$ & 0.10 & $-2.5^{\mathrm{a}}$ & 0.27 & \\
\hline
\end{tabular}

Each fish provided two fillets, where one fillet were either stored untreated $(C)$ or electrically stimulated with for $3 \mathrm{~min}(\mathrm{E})$ prior to storage

In each column different lower case superscripts a, b represents a significant at $* P<0.05, * * P<0.005$, *** $P<0.0005$

difference in $b^{*}$ values was seen $(P>0.22$, paired $t$-test $)$ when measuring colour instrumentally (Minolta, Table 3).

Colour analysis using computer imaging (Table 2) showed that electrically stimulated fillets were significantly whiter $(P<0.05$, paired $t$-test $)$ and less reddish compared to the control fillets $(P<0.05$, paired $t$-test $)$. Over 7 days of storage the whiteness increased $(P<0.005$, paired $t$-test $)$ as the reddishness decreased $(P<0.005$, paired $t$-test $)$, but the difference in whiteness and reddishness between control and electrical stimulated fillets remained $(P<0.05$, paired $t$-test $)$.

\section{Fillet texture}

As demonstrated in Fig. 2, the muscle shear force was dependent upon season $(P<0.0005$, ANCOVA) increasing approximately two folds from June to November. Adding $\mathrm{pH}$ and weight as covariate showed that the shear force was also dependent on end $\mathrm{pH}(P<0.0005$. ANCOVA $)$, but not initial $\mathrm{pH}$ at slaughter $(P>0.12, \beta>0.33$, ANCOVA) or weight ( $P>0.32, \beta>0.16$, ANCOVA).

Looking at the results from March separately, testing possible effect of photoperiod (LDN vs. LD24:0), sex (males vs. females) and maturation (immature vs. mature), showed 


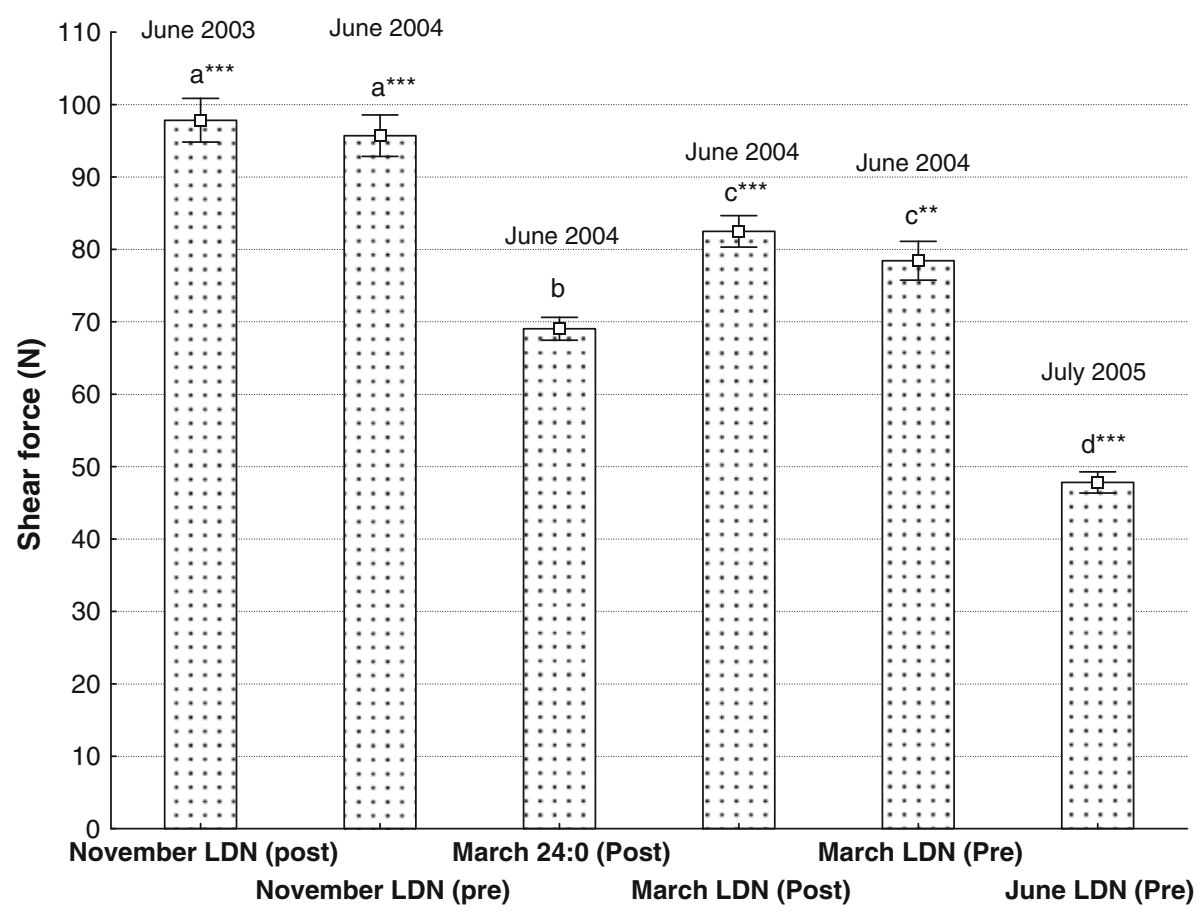

Fig. 2 Average shear force $(N) \pm 0.95 *$ SE. (whiskers) after 7 days of storage from pre or post rigor filleted turbot farmed under continuous (LD24:0) or natural (LDN) daylight, slaughtered in March $(N=30)$, June $(N=10)$ and November $(N=20)$. Dates on top represent time of hatching. Different lower case superscripts $\mathbf{a}, \mathbf{b}, \mathbf{c}, \mathbf{d}$ represents a significant difference between groups at $* P<0.05$, $* * P<0.005$ and $* * * P<0.0005$

that fish reared under continuous light had significantly lower shear forces than fish reared under LDN $(P<0.005$, Tukey post hoc). Although pre rigor fillets seemingly displayed a lower shear force compared to post rigor filleted fish, there was no significant difference in shear force between these two groups of fish $(P>0.32$, Tukey post hoc, Fig. 2$)$. The differences and variation between and in-between the groups could be explained by the sex and degree of maturation, both influencing an equal share on the shear force $(P<0.005$, ANCOVA, Fig. 3). In line with the overall analysis, the changes of shear force could partly be explained by the end $\mathrm{pH}(P<0.0005$, ANCOVA $)$, but not weight $(P>0.89, \beta>0.05$, ANCOVA).

Comparing electrical stimulated fillets against the control fillets show that electrical stimulation causes a overall $4 \%$ decrease in shear force $(P<0.05$, paired $t$-test, Fig. 4$)$. However, a significant drop in shear force amongst electrically stimulated fillets was only observed in fish slaughtered in November $(P<0.005$, paired $t$-test), but not in March $(P>0.37$, paired $t$-test $)$ nor in June $(P>0.48$, paired $t$-test $)$.

\section{Hardness}

There were no difference in hardness between $\mathrm{C}$ and $\mathrm{E}$ fillets measured as breaking force $(P>0.09$, paired $t$-test, Table 4$)$, maximum force recorded $(P>0.23$, paired $t$-test $)$, at $60 \%(P>0.35$, paired $t$-test $)$ and 40\% $(P>0.19$, paired $t$-test $)$ compression. There were, 


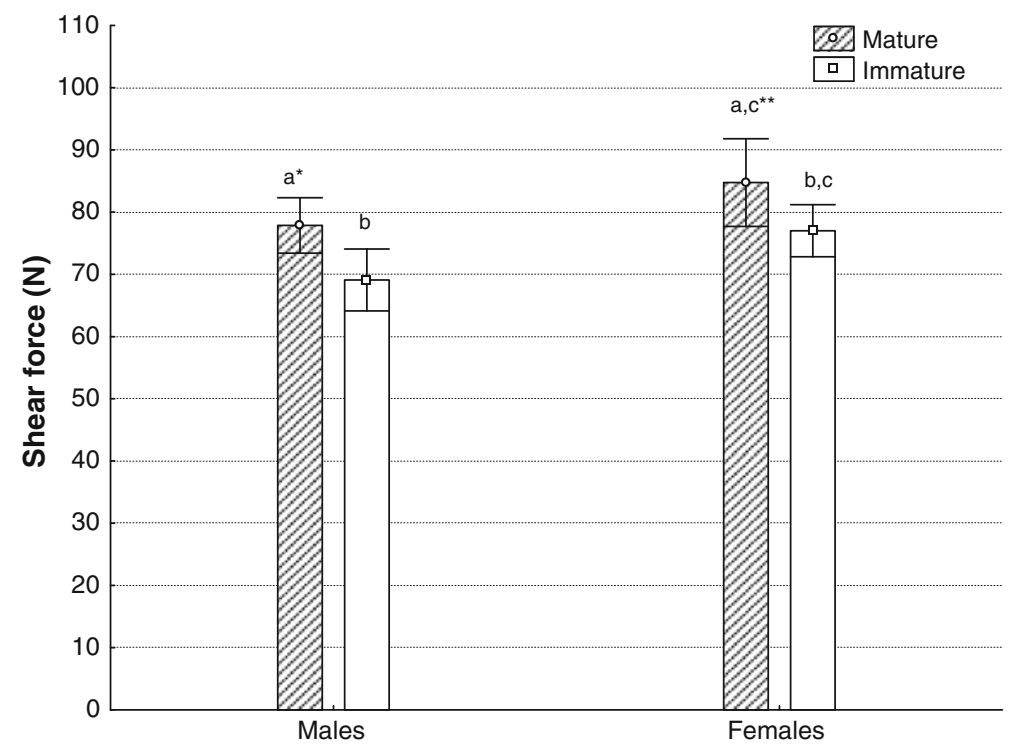

Fig. 3 Average shear force $(N) \pm 0.95 * \mathrm{SE}$ (whiskers) after 7 days of storage of mature and immature males and females slaughtered in March. Different lower case superscripts $\mathbf{a}, \mathbf{b}, \mathbf{c}$ represents a significant difference between different groups at $* P<0.05$, $* * P<0.005$ and $* * * P<0.0005$

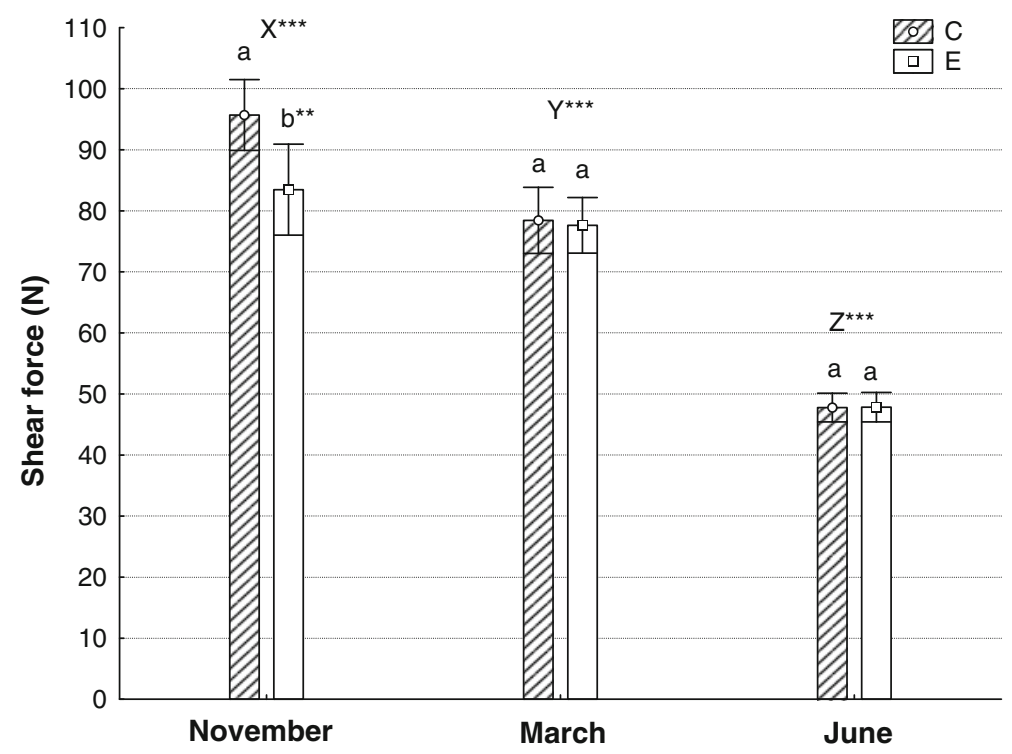

Fig. 4 Average shear force $(N) \pm 0.95 * \mathrm{SE}$ (whiskers) after 7 days of storage from pre rigor filleted fillets of turbot slaughtered in March $(n=10)$, June $(n=10)$ and November $(n=10)$. Each fish provided 2 fillets, where one fillet were either stored untreated (C) or electrically stimulated for 3 min (E) prior to storage. Different lower case superscripts $\mathbf{a}, \mathbf{b}$ represents a significant difference between $\mathrm{C}$ and $\mathrm{E}$ fillets, while capital letter $X, Y, Z$ represents a significant difference between month at $* P<0.05$, $* * P<0.005$ and $* * * P<0.0005$ 
Table 4 Least square mean of fillet hardness and breaking strength $(N) \pm 0.95 *$ SE evaluated as the force recorded during exactly at 40 and $60 \%$ compression or maximum force recorded during an $80 \%$ compression cycle in electrically stimulated (E) and control (C) fillets of turbot slaughtered in March and June

\begin{tabular}{|c|c|c|c|c|c|c|c|c|c|c|}
\hline \multirow[t]{3}{*}{ Samplin } & \multicolumn{10}{|c|}{ Force $(N)$} \\
\hline & & \multicolumn{2}{|l|}{ Breaking } & \multicolumn{2}{|l|}{$\operatorname{Max}$} & \multicolumn{2}{|l|}{$60 \%$} & \multicolumn{2}{|l|}{$40 \%$} & \multirow[b]{2}{*}{$n$} \\
\hline & & LS mean & SE & LS mean & SE & LS mean & SE & LS mean & SE & \\
\hline \multirow[t]{2}{*}{ March } & $\mathrm{C}$ & 92 & 2.4 & 124 & 3.6 & 83 & 2.2 & 46 & 2.3 & \\
\hline & E & 89 & 2.4 & 123 & 3.7 & 86 & 2.2 & 52 & 2.3 & \\
\hline \multirow[t]{2}{*}{ June } & $\mathrm{C}$ & 81 & 2.4 & 118 & 3.6 & 77 & 2.5 & 51 & 2.3 & \\
\hline & $\mathrm{E}$ & 79 & 2.4 & 111 & 3.7 & 74 & 2.6 & 45 & 2.3 & \\
\hline \multicolumn{11}{|c|}{ ANCOVA } \\
\hline \multicolumn{2}{|c|}{ Sample height } & \multicolumn{2}{|l|}{ NS } & \multicolumn{2}{|l|}{$* * *$} & \multicolumn{2}{|l|}{$* * *$} & \multicolumn{3}{|l|}{ NS } \\
\hline \multicolumn{2}{|c|}{ March versus June } & \multicolumn{2}{|l|}{$* * *$} & \multicolumn{2}{|l|}{$*$} & \multicolumn{2}{|l|}{$* *$} & \multicolumn{3}{|l|}{ NS } \\
\hline \multicolumn{2}{|c|}{$C$ versus $E$} & \multicolumn{2}{|l|}{ NS } & \multicolumn{2}{|l|}{ NS } & \multicolumn{2}{|l|}{ NS } & \multicolumn{2}{|l|}{ NS } & \\
\hline
\end{tabular}

Asterisks indicate the level of significance at $* P<0.05$, *** $P<0.0005$ and NS represents $P>0.05$

however, significant differences in hardness according to season, where fish slaughtered in March required higher the forces to break muscle structure $(P<0.0005$, ANCOVA) and in general harder than fish slaughtered in June measured at $60 \%$ compression $(P<0.005$, ANCOVA) or as highest force recorded $(P<0.05$, ANCOVA). At $40 \%$ compression, there were no significant differences between fish slaughtered in March or June $(P>0.75$, ANCOVA).

\section{Discussion}

Results on textural properties, measured as shear force (Figs. 2, 3, 4) and hardness (Table 4), clearly suggest that changes in quality is more influenced by season and rearing conditions rather than anaerobic muscle activity. Previous studies on Atlantic halibut (Haugen et al. 2006) show the shear forces of the muscles increases in periods where the fish displayed poor growth, depending on collagen content and increased hydroxylysyl pyridinoline cross link concentrations (Hagen et al. 2007). Theoretically, this could explain why turbot were softer in June than in March or November. However, since the fish came from three different farms, originating from three different strains, hatched at different times and fed with three different feeds, there is an underlying uncertainty whether changes could be explained from genetics and rearing conditions, rather than season. Turbot, like most other farmed species from the temperate zone, grows according to photoperiod, temperature, sex and maturation (Imsland et al. 1995, 1997, 2003). As illustrated in Figs. 2 and 3 , the textural properties in farmed turbot displayed almost a reflection of its expected growth, where the shear force was highest in periods expecting poor growth, during the winter months and during maturation. These changes demonstrate that growth may influence the texture of fish, but cannot solely explain the large difference from November and June. In Halibut it has been shown that shear forces increases almost two fold during winter month until maturation early spring (Hagen et al. 2007), not very far from obtained results in Fig. 2. Although a higher growth rate is expected in June, it is interesting notice 
that fish used in June was from a domesticated strain, and based on date of hatching and weight at slaughter (Table 1), shows that this fish had an overall better growth. This suggests that genetics may be an important variable explaining some differences found in quality and should in the future be studied in more extent.

It is also important to ask how stress, anaerobic muscle activity and muscle $\mathrm{pH}$ may influence end quality. When sampling halibut throughout the year, Hagen et al. (2007) clearly demonstrated that shear forces were more related to collagen content rather than muscle $\mathrm{pH}$. Comparing fillets from the same or amongst fish show that electrical stimulation of Atlantic salmon (Roth et al. 2008), rainbow trout (Robb et al. 2000), Chinook salmon and turbot (Roth et al. 2007a) displayed similar results as that found in the present study (Table 1), where forced muscle contractions associated with electrical stimulation caused an immediate $\mathrm{pH}$ drop of $0.4-0.5$ units in muscle. Question rises whether muscles are exhausted at such a degree that it resembles an acute stress reaction in fish followed by flight reactions associated with anaerobic muscle activity. Previous studies with electrical stimulation of loach (cobitis biswae) show the muscles PCr and ATP levels are almost depleted after a $24 \mathrm{~s}$ exposure of $5 \mathrm{~V}, 10 \mathrm{~Hz}$ pDC (Chiba et al. 1990). This represents approximately 240 muscle contractions, whereas this study gives the potential of stimulating 900 muscle contractions although the muscles were clearly fatigued within 2 min.

On quality, results on Atlantic salmon show that electrically stimulated fillets do have slight increase in whiteness, drip loss and softer texture as compared to the untreated fillet (Roth et al. 2008). Drip losses in turbot were, however, more than three times higher than what was observed in Atlantic salmon (0.6-0.8\%). Higher drip losses in turbot can be explained by the fact that the turbot fillet is relatively lean compared to the salmon fillet. Pre rigor fillets from lean species such as Atlantic cod (Gadus morhua) have approximately 6-7\% drip loss after 7 days of ice storage (Kristoffersen et al. 2007) and will during rigor shrink by $20 \%$ (Stien et al. 2005). For species with high values of body fat, such as Atlantic salmon, the fillets will shrink approximately by $10 \%$ (Kiessling et al. 2006). Being a partially lean species, turbot seem to lie in between both in terms of drip loss and fillet shrinkage (Table 2).

On colour, results on turbot (Table 3) show similar tendencies as for salmon (Roth et al. 2008; Robb et al. 2000), where electrically stimulated fillets had increased lightness as compared to control fillets. Apparently the loss of reddishness observed in electrically stimulated fillets (Table 2) is a result of less blood. This corresponds with a previous study by Roth et al. (2007b) where use of computer imaging on post rigor filleted and unbled turbot revealed that percussive killed fish had higher reddishness and less whiteness than and electrically stimulated carcasses. Forcing blood out using electrical stimulation might only be feasible in newly killed animals, as electrical exposure on a live specimen would cause an autonomic release of catecholamines (Schreck et al. 1976), potentially known to redirect the blood from the gut and into muscles (Farrell et al. 2001).

In summary it can be concluded that an early post mortem softening of turbot flesh is related to anaerobe glycolysis, which causes a higher drip loss during cold storage, but the effect can be considered a minor event compared to seasonal events such as growth and maturation and, to some extent, sex related attributes.

Acknowledgments These experiments was a part of the EC-CRAFT project no. 508070, TURPRO and AVS project R032-05. We would like to thank all the involved project partners A. Coelho e Castro, Portugal; Ecomares, Germany; Llyn Aquaculture Ltd., UK; Silfurstjarnan, Iceland; and Zeeland Vis BV, Netherlands. Also thanks to Soffia Vala Tryggvadottir at the Icelandic Fisheries Laboratory (Matis), Sigurd Øines at Norconserv, Laila Løvås Roth for technical support during the experiment and Edward Schram at Wageningen IMARES, The Netherlands. 
Open Access This article is distributed under the terms of the Creative Commons Attribution Noncommercial License which permits any noncommercial use, distribution, and reproduction in any medium, provided the original author(s) and source are credited.

\section{References}

Azam K, Mackie IM, Smith J (1989) The effect of slaughter method on the quality of Rainbow trout (Salmo gairdneri) during storage on ice. Int J Food Sci Technol 24:69-79

Boggess TS, Heaton EK, Beuchat LR (1973) Procedure for processing smoked channel Catfish (Ictalurus punctatus). J Milk Food Technol 36:469-473

Bouza C, Presa P, Castro J, Sanchez L, Martinez P (2002) Allozyme and microsatellite diversity in natural and domestic populations of turbot (Scophthalmus maximus) in comparison with other Pleuronectiformes. Can J Fish Aquat Sci 59:1460-1473. doi:10.1139/f02-114

Chiba M, Hamaguchi M, Asai T, Tokuno T, Chichibu S (1990) In vivo P-NMR analysis of the electric anesthetized loach, Corbis biswae. Comp Biochem Physiol 97A:385-389

Espe M, Ruohonen K, Bjornevik M, Froyland L, Nortvedt R, Kiessling A (2004) Interactions between ice storage time, collagen composition, gaping and textural properties in fanned salmon muscle harvested at different times of the year. Aquaculture 240:489-504. doi:10.1016/j.aquaculture.2004.04.023

Farrell AP, Thorarensen H, Axelsson M, Crocker CE, Gamperl AK, Cech JJ (2001) Gut blood flow in fish during exercise and severe hypercapnia. Comp Biochem Physiol A 128:551-563

Fletcher GC, Hallett IC, Jerrett AR, Holland AJ (1997) Changes in the fine structure of the myocommatamuscle fibre junction related to gaping in rested and exercised muscle from King salmon (Oncorhynchus tshawytscha). Food Sci Technol 30:246-252

Hagen O, Solberg C, Sirnes E, Johnston IA (2007) Biochemical and structural factors contributing to seasonal variation in the texture of farmed Atlantic halibut (Hippoglossus hippoglossus L.) flesh. J Agric Food Chem 55:5803-5808. doi:10.1021/jf063614h

Haugen T, Kiessling A, Olsen RE, Rørå MB, Slinde E, Nortvedt R (2006) Seasonal variations in muscle growth dynamics and selected quality attributes in Atlantic halibut (Hippoglossus hippoglossus L.) fed dietary lipids containing soybean and/or herring oil under different rearing conditions. Aquaculture 261:565-779. doi:10.1016/j.aquaculture.2006.08.012

Imsland AK, Folkvord A, Stefansson SO (1995) Growth, oxygen consumption and activity of juvenile turbot (Scophthalmus maximus L.) reared under different temperatures and photoperiods. Neth J Sea Res 34:149-159. doi:10.1016/0077-7579(95)90023-3

Imsland AK, Folkvord A, Jonsdottir ODB, Stefansson SO (1997) Effects of exposure to extended photoperiods during the first winter on long-term growth and age at first maturity in turbot (Scophthalmus maximus). Aquaculture 159:125-141. doi:10.1016/S0044-8486(97)00152-X

Imsland AK, Dragsnes M, Stefansson SO (2003) Exposure to continuous light inhibits maturation in turbot (Scophthalmus maximus). Aquaculture 219:911-919. doi:10.1016/S0044-8486(03)00034-6

Jerrett AR, Holland AJ (1998) Rigor tension development in excised "rested", "partially exercised" and "exhausted" chinook salmon white muscle. J Food Sci 63:48-52. doi:10.1111/j.1365-2621.1998. tb15673.x

Jerrett AR, Stevens J, Holland AJ (1996) Tensile properties of white muscle in rested and exhausted chinook salmon (Oncorhynchus tshawytscha). J Food Sci 61:527-532. doi:10.1111/j.1365-2621.1996.tb131 49.x

Jerrett AR, Holland AJ, Cleaver SE (1998) Rigor contractions in "rested" and "partially exercised" chinook salmon white muscle as affected by temperature. J Food Sci 63:53-56. doi:10.1111/j.1365-2621. 1998.tb15674.x

Johnston IA, Bickerdike R, Li XJ, Dingwall A, Nickel D, Alderson R, Campbell P (2007) Fast growth was not associated with an increased incidence of soft flesh and gaping in two strains of Atlantic salmon (Salmo salar) grown under different environmental conditions. Aquaculture 265:148-155. doi: 10.1016/j.aquaculture.2007.01.045

Kiessling A, Espe M, Ruohonen K, Morkore T (2004) Texture, gaping and colour of fresh and frozen Atlantic salmon flesh as affected by pre-slaughter iso-eugenol or $\mathrm{CO} 2$ anaesthesia. Aquaculture 236:645-657. doi:10.1016/j.aquaculture.2004.02.030

Kiessling A, Stien LH, Torslett V, Suontarna J, Slinde E (2006) Effect of pre- and post-mortem temperature on rigor in Atlantic salmon muscle as measured by four different techniques. Aquaculture 259: 390-402. doi:10.1016/j.aquaculture.2005.11.008 
Kristoffersen S, Vang B, Larsen R, Olsen RL (2007) Pre-rigor filleting and drip loss from fillets of farmed Atlantic cod (Gadus morhua L.). Aquacult Res 38:1721-1731

Lavety J, Afolabi OA, Love RM (1988) The connective tissues of fish. 9. Gaping in farmed species. Int J Food Sci Technol 23:23-30

Love RM (1975) Variability in Atlantic cod (Gadus morhua) from the Northeast Atlantic: a review of seasonal and environmental influences on various attributes to the flesh. J Fish Res Board Can 32:2333-2342

Morkore T, Rorvik KA (2001) Seasonal variations in growth, feed utilisation and product quality of farmed Atlantic salmon (Salmo salar) transferred to seawater as $0+$ smolts or $1+$ smolts. Aquaculture 199: 145-157. doi:10.1016/S0044-8486(01)00524-5

Morzel M, Sohier D, van de Vis H (2003) Evaluation of slaughtering methods for turbot with respect to animal welfare and flesh quality. J Sci Food Agric 83:19-28. doi:10.1002/jsfa.1253

Proctor MRM, McLoughlin JV (1992) The effects of anaesthesia and electrical stunning on chemical changes in the myotomal muscle of Salmo salar post mortem. Proc R Ir Acad [B] 92:53-59

Robb DHF, Kestin SC, Warriss PD (2000) Muscle activity at slaughter: I. Changes in flesh colour and gaping in rainbow trout. Aquaculture 182:261-269. doi:10.1016/S0044-8486(99)00273-2

Roth B, Slinde E, Arildsen J (2006) Pre or post mortem muscle activity in Atlantic salmon (Salmo salar). The effect on rigor mortis and the physical properties of flesh. Aquaculture 257:504-510. doi: 10.1016/j.aquaculture.2005.10.021

Roth B, Imsland A, Gunnarsson S, Foss A, Schelvis R (2007a) Slaughter quality and rigor contraction in farmed turbot (Scophthalmus maximus); a comparison between different stunning methods. Aquaculture 272:754-761. doi:10.1016/j.aquaculture.2007.09.012

Roth B, Stien LH, Schelvis R, Foss A, Nortvedt R, Imsland A (2007b) Exsanguination of turbot and the effect on fillet quality measured mechanically, sensory and with computer vision. J Food Sci 72:525531. doi:10.1111/j.1750-3841.2007.00540.x

Roth B, Oeines S, Rotabakk BT, Birkeland S (2008) Using electricity as a tool in quality studies of Atlantic salmon. Eu J Food Sci Technol 227:571-577

Ruff N, Fitzgerald RD, Cross TF, Teurtrie G, Kerry JP (2002a) Slaughtering method and dietary alphatocopheryl acetate supplementation affect rigor mortis and fillet shelf-life of turbot Scophthalmus maximus L. Aquacult Res 33:703-714. doi:10.1046/j.1365-2109.2002.00707.x

Ruff N, Fitzgerald RD, Cross TF, Kerry JP (2002b) Comparative composition and shelf-life of fillets of wild and cultured turbot (Scophthalmus maximus) and Atlantic halibut. Aquacult Res 10:241-256

Schreck CB, Whaley RA, Bass ML, Maughan OE, Solazzi M (1976) Physiological-responses of rainbowtrout (Salmo-Gairdneri) to Electroshock. J Fish Res Board Can 33:76-84

Sigurgisladottir S, Sigurdardottir MS, Ingvarsdottir H, Torrissen OJ, Hafsteinsson H (2001) Microstructure and texture of fresh and smoked Atlantic salmon. Salmo salar L., fillets from fish reared and slaughtered under different conditions. Aquacult Res 32:1-10. doi:10.1046/j.1365-2109.2001.00503.x

Stien LH, Hirmas E, Bjornevik M, Karlsen O, Nortvedt R, Rora AMB, Sunde J, Kiessling A (2005) The effects of stress and storage temperature on the colour and texture of pre-rigor filleted farmed cod (Gadus morhua L.). Aquacult Res 36:1197-1206. doi:10.1111/j.1365-2109.2005.01339.x

Veland JO, Torrissen OJ (1999) The texture of Atlantic salmon (Salmo salar) muscle as measured instrumentally using TPA and Warner-Brazler shear test. J Sci Food Agric 79:1737-1746. doi:10.1002/ (SICI)1097-0010(199909)79:12<1737::AID-JSFA432>3.0.CO;2-Y 